\title{
Risk factors for allergic diseases: a cross-sectional survey of 9,501 Chinese preschool-aged children
}

\author{
Min Yang ${ }^{1,2}$, Xiangling Deng ${ }^{1,2}$, Shunan Wang ${ }^{1,2}$, Kundi Wang $^{2}$, Wenquan Niu ${ }^{3}$, Zhixin Zhang ${ }^{2,4}$ \\ ${ }^{1}$ Graduate School, Beijing University of Chinese Medicine, Beijing, China; ${ }^{2}$ Department of Pediatrics, China-Japan Friendship Hospital, Beijing, \\ China; ${ }^{3}$ Institute of Clinical Medical Sciences, China-Japan Friendship Hospital, Beijing, China; ${ }^{4}$ International Medical Services, China-Japan \\ Friendship Hospital, Beijing, China \\ Contributions: (I) Conception and design: Z Zhang; (II) Administrative support: Z Zhang; (III) Provision of study materials or patients: $M$ Yang, X \\ Deng, K Wang, S Wang; (IV) Collection and assembly of data: M Yang, S Wang, X Deng; (V) Data analysis and interpretation: M Yang, X Deng; (VI) \\ Manuscript writing: All authors; (VII) Final approval of manuscript: All authors. \\ Correspondence to: Wenquan Niu, PhD and Zhixin Zhang, MD. No. 2 Yinghua East Street, Chao Yang District, Beijing 100029, China. \\ Email: niuwenquan_shcn@163.com or zhangzhixin032@163.com.
}

Background: Childhood allergic diseases are increasing worldwide with unprecedented complexity and severity, and they cause a major burden on health and healthcare costs. We aimed to identify potential factors, both in isolation and in combination, associated with allergic diseases among preschool-aged children, and to construct a nomogram prediction model based on significant factors.

Methods: We cross-sectionally recruited 9,501 preschool-aged children from 30 kindergartens in Beijing and Tangshan. Allergic diseases were ascertained according to the "International Study of Asthma and Allergies in Childhood" questionnaire. Risk for allergic diseases is quantified by odds ratio (OR) with $95 \%$ confidence interval (CI).

Results: Four factors were identified to be independently, consistently, and significantly associated with the risk for allergic diseases overall and by four clinical manifestations separately, including bedtime (per 1 hour late) (taking asthma/wheezing as an example, OR, 95\% CI, P: 1.21, 1.08 to 1.35, 0.001), outdoor activities $\leq 1.5 \mathrm{~h}$ per day $(1.45,1.26$ to $1.68,3.77 \mathrm{E}-07)$, family history of allergic diseases $(2.23,1.92$ to $2.60,0.00 \mathrm{E}+00)$, and antibiotic use during childhood (3.64, 2.44 to $5.42,1.66 \mathrm{E}-10)$. Further analyses revealed that family history of allergic diseases acted with antibiotic use during childhood in an additive manner. For practical reasons, risk prediction nomogram models were constructed for allergic diseases respectively in Beijing and Tangshan based on significant and conventional factors, and the prediction accuracy was good, with the C-index 69\% in Tangshan and 68\% in Beijing (both $\mathrm{P}=0.00 \mathrm{E}+00$ ).

Conclusions: Our findings identified four factors in significant association with the risk for allergic diseases, and in particular family history of allergic diseases and antibiotic use during childhood acted additively.

Keywords: Allergic disease; risk factor; preschool-aged children; association; nomogram

Submitted Mar 26, 2021. Accepted for publication Jul 02, 2021.

doi: $10.21037 /$ tp-21-124

View this article at: https://dx.doi.org/10.21037/tp-21-124

\section{Introduction}

Childhood allergic diseases have attracted global attention owing to increasing prevalence rates and unprecedented complexity and severity (1). As demonstrated by the
International Study of Asthma and Allergies in Childhood (ISAAC) phase III, the prevalence of childhood asthma and allergic rhinitis in the majority of Asia-Pacific regions exhibited an increasing trend during the period from 2001 to 2010 (2). In China, the average prevalence of 
childhood asthma, allergic rhinitis, and eczema across eight metropolitan cities in 2005, was estimated to be $3.3 \%$, $9.8 \%$, and $5.5 \%$, respectively (3). A large, population-based survey done in Shanghai revealed that excessive gestational weight gain may be a risk factor for childhood allergic diseases including asthma, allergic rhinitis, eczema, and food/drug allergy (4). It is worth noting that childhood allergic diseases generally persist into adulthood, and result in morbidity throughout life as chronic diseases (5). What's worse, allergic diseases can markedly interfere with normal activities, seriously impact an individual's quality of life, and even cause deaths, which append a major burden on health and healthcare costs (6). Therefore, a better understanding of the risk profiles responsible for allergic diseases in children is of clinical and public health importance, and prevention of allergic diseases through identification and management of potential risk factors is a priority.

In practice, allergic conditions in children are of high prevalence rates $(4,6)$. For instance, the prevalence rates of allergic diseases in children 3-14 years of age in Shanghai were $20.2 \%$ for asthma/wheezing, $28.8 \%$ for allergic rhinitis, $38.8 \%$ for eczema, and $11.9 \%$ for food/ drug allergy (4). It is widely accepted that the causes of allergic diseases are complex and multifactorial in nature. Over the past decades, great endeavors have been devoted to identify and characterize potential factors for allergic diseases, yet no consensus is attained thus far on how many factors and which factors are actually involved. For instance, studies conducted in Chinese and Danish populations have reported a positive association between antibiotics exposures during the early lifetimes and childhood asthma and allergies $(7,8)$. However, an international survey across 28 countries failed to support this association (9). The case was the same for the association of outdoor physical exercise with eczema among adolescents, with Anveden Berglind et al. reporting a protective association in Sweden (10), but Al-Sahab et al. instead claiming a risky association in Lebanese (11). It is possible that the reasons behind these inconsistent observations are due to the involvement of children of diverse descent origins, the lack of sufficient statistical power to detect significance, and the underexploration of promising factors for allergic diseases.

To yield more information, we in this large, crosssectional study, aimed to identify potential factors associated with childhood allergic diseases, and importantly we attempted to test the hypothesis that the contribution of some individual factors to childhood allergic diseases might hinge upon the presence of others. Finally for practical reasons, a nomogram model predicting childhood allergic diseases was constructed based on significant factors identified above.

We present the following article in accordance with the STROBE reporting checklist (available at https://dx.doi. org/10.21037/tp-21-124).

\section{Methods}

\section{Study design}

The cross-sectional survey was simultaneously done in Beijing and Tangshan during the period from September to December in 2020. The implementation of this survey was reviewed and approved by the Ethics Committee of ChinaJapan Friendship Hospital, and was in compliance with the principles of the Declaration of Helsinki (as revised in 2013). Parents or guardians of all involved children read and given informed consent prior to participation.

\section{Study subjects}

Study subjects were restricted to preschool-aged children attending junior to senior classes in kindergartens. Utilizing a stratified cluster random sampling strategy, 4 out of 16 districts in Beijing and 2 out of 7 districts in Tangshan were selected. Within each district, 5 kindergartens were randomly selected, and 30 kindergartens were included finally. Self-designed questionnaires were sent to parents or guardians of 10,441 children, and $98 \%$ of them $(n=10,230)$ returned questionnaires within the scheduled time.

Children were excluded from this survey if they suffered from major illnesses including but not limited to chronic kidney diseases, hypothyroidism, or congenital heart diseases. All questionnaires were strictly reviewed by trained staff, and finally 9,501 of them were deemed eligible for inclusion.

\section{Data collection}

Data from children and their parents on possible risk profiling of pediatric allergic diseases were collected via questionnaires.

From children, surveyed data included date of birth, sex, region, bedtime at night, time spent on outdoor activities at workdays and weekends, second-hand smoke exposure, antibiotic use during childhood, pet raising, gestational age, delivery mode, birth weight, infancy feeding type, 
breastfeeding duration, and solid food consumption age. Body weight (to the nearest $0.1 \mathrm{~kg}$ ) and height (to the nearest $0.1 \mathrm{~cm}$ ) of children were measured by trained healthcare physicians.

From their parents, self-reported data on age, sex, weight, height, education, family income, maternal pregnancy smoking, gestational diabetic mellitus, and family history of allergic diseases were recorded.

\section{Quality control}

Kindergarten teachers were responsible for sending electronic questionnaires to parents or guardians of all participating children, and completed questionnaires were abstracted online. Data were transformed from electronic questionnaires to a Microsoft Office Excel ${ }^{\mathrm{TM}}$ spreadsheet and were strictly checked by trained staff. In case of missing or uncertain records, parents or guardians were contacted for clarity.

\section{Definition of allergic diseases}

The International Study of Asthma and Allergies in Childhood (ISAAC) questionnaire (12), which is commonly used among preschool children, was adopted to ascertain childhood allergic diseases (13-15). Briefly, information both on ever-diagnosed diseases and current symptoms was obtained to identify childhood asthma/wheezing, allergic rhinitis, and eczema. The determination of food/drug allergy was mainly based on questions related to physician diagnosis. More detailed information on each allergic disease is described in Table S1.

\section{Definition of factors under survey}

For children, body mass index (BMI) was calculated as measured body weight divided by height squared $\left(\mathrm{kg} / \mathrm{m}^{2}\right)$. Time spent on outdoor activities everyday was calculated as the sum of time both on workdays $\times 5$ and weekends $\times 2$ divided by 7 , then was divided into two groups according to the mean value at 1.5 hours. Second-hand smoke exposure was categorized into four groups including no exposure, 1-5 cigarettes, 5-10 cigarettes, and $>10$ cigarettes every day. Pet raising and antibiotic use during childhood were defined as yes or no. Infancy feeding type included exclusive breast feeding, partial breast feeding, and exclusive formula feeding. Breastfeeding duration was classified as $<12$ and $\geq 12$ months. Solid food consumption age was recorded in months. Gestational age was divided into $<37,37-42$, and $>42$ weeks. Delivery mode included vaginal delivery and caesarean section.

For parents or guardians, maternal BMI and paternal BMI were calculated from self-reported body weight and height. Parental age and maternal age were calculated as the difference between the date of child's birth and parents' birth. Maternal gestational diabetes mellitus (GDM) and family history of allergic diseases diagnosed by doctors from second-class or above hospitals, were recorded. Maternal pregnancy smoking was defined as smoking and nonsmoking. Education was categorized as doctor's degree or above, master's degree, bachelor's degree, and high school degree or below. Family income (RMB per year) was categorized as $\geq 300,000,100,000-300,000$, and $<100,000$.

\section{Statistical analyses}

All study children were defined as affected and unaffected individuals by each of the following clinical manifestations, including asthma/wheezing, allergic rhinitis, eczema, and food/drug allergy. The distributions of continuous variables were assessed for normality by use of the skewness and kurtosis tests. Skewed continuous variables are expressed as median (interquartile range) and normally distributed variables as mean (standard deviation). Categorical variables are expressed as number (percentage). Between-group comparisons were implemented by $t$-test or rank-sum test or $\chi^{2}$ test, where appropriate. To identify significant factors associated with childhood allergic diseases, univariate Logistic regression analyses were first implemented without considering any confounders, and next multivariable Logistic regression analyses were done after initially adjusting for age, sex, and region, and additionally for BMI, second-hand smoke exposure, pet raising, maternal pregnancy smoking, gestational age, delivery mode, birth weight, infancy feeding type, breastfeeding duration, solid food consumption age, maternal age at delivery, paternal age at delivery, maternal $\mathrm{BMI}$, paternal BMI, maternal education, paternal education, and family income for four clinical manifestations separately and as a whole. In addition, multivariable Logistic regression analyses were also conducted to examine the combination of any two significant factors for the prediction of allergic diseases after adjusting for confounding factors. Risk for allergic diseases is quantified by odds ratio (OR) with $95 \%$ confidence interval (CI).

To evaluate the performance of individual factors and integrated models, study children were randomly split 
into the training set (60\%) and the testing set (40\%). The difference in risk estimates between training set and testing set was evaluated by the $Z$ tests at a significance level of 0.05 .

Prediction accuracy of significant factors was appraised from calibration and discrimination aspects. Calibration statistics includes Akaike information criterion (AIC), Bayesian information criterion (BIC), $-2 \log$ likelihood ratio test, as well as the Hosmer-Lemeshow test. Discrimination statistics includes the integrated discrimination improvement (IDI) and the area under the receiver operating characteristic (ROC) to justify the improvement in prediction performance. Additionally, net benefits for adding significant risk factors were justified by decision curve analysis (16).

Finally, based on significant factors associated with allergic diseases as a whole, risk prediction nomogram models were constructed in Beijing and Tangshan, respectively, and these models were generated by the $\mathrm{R}$ language version 3.5 .2 for Windows.

Unless otherwise reported, statistical analyses were completed using the STATA software (Stata Corp, TX, USA) version 14.0 for Windows. Two-sided $\mathrm{P}$ value less than $5 \%$ was reported to be statistically significant, and Bonferroni correction was used for multiple comparisons. Statistical power was estimated using the PS Power and Sample Size Calculations software version 3.0.

\section{Results}

\section{Baseline characteristics}

As this survey enrolled children from Beijing and Tangshan, the comparisons of age and sex, as well as excluded questionnaires are presented in Table S2.

The baseline characteristics of study children are shown in Table S3 for allergic diseases as a whole and Table 1 by four clinical manifestations. In total, surveyed data from 9,501 preschool-aged children (4,823 boys and 4,678 girls) were extracted. The mean age of all children was 4.58 years old. The prevalence rate of allergic diseases overall was $46.61 \%$, and by clinical manifestations, the prevalence rates of asthma/wheezing, allergic rhinitis, eczema, and food/ drug allergy were $8.88 \%, 30.45 \%, 33.51 \%$, and $13.81 \%$, respectively.

As for the co-occurrence of two allergic diseases, asthma/wheezing and allergic rhinitis accounted for $5.3 \%(505 / 9,501)$, asthma/wheezing and food/drug allergy $2.5 \%(234 / 9,501)$, asthma/wheezing and eczema $4.8 \%(460 / 9,501)$, allergic rhinitis and eczema $15.6 \%$
$(1,481 / 9,501)$, allergic rhinitis and food/drug allergy $6.7 \%(641 / 9,501)$, eczema and food/drug allergy $8.6 \%$ $(813 / 9,501)$. As for the co-occurrence of three allergic diseases, asthma/wheezing, allergic rhinitis and eczema accounted for 3.2\% (305/9,501), asthma/wheezing, allergic rhinitis and food/drug allergy $1.7 \%(161 / 9,501)$, asthma/ wheezing, eczema and food/drug allergy 1.8\% (175/9,501), allergic rhinitis, eczema and food/drug allergy $4.9 \%$ $(463 / 9,501)$. As for the co-occurrence of four allergic diseases, asthma/wheezing, allergic rhinitis, eczema and food/drug allergy accounted for 130/9,501 (1.4\%).

\section{Identification of potential factors}

After multivariable adjustment, bedtime per 1 hour late (OR, 95\% CI, P for asthma/wheezing: $1.21,1.08$ to 1.35 , $0.001)$, outdoor activities less than $1.5 \mathrm{~h}$ per day $(1.45,1.26$ to $1.68,3.77 \mathrm{E}-07)$, antibiotic use during childhood (3.64, 2.44 to $5.42,0.00 \mathrm{E}+00), \operatorname{GDM}(1.37,1.09$ to $1.73,0.008)$, and family history of allergic diseases $(2.23,1.92$ to 2.60 , $1.66 \mathrm{E}-10)$ were found to be independently and consistently associated with the significant risk of childhood allergic diseases overall and by clinical manifestations (asthma/ wheezing, allergic rhinitis, eczema, and food/drug allergy), even after the Bonferroni correction (Table 2).

To evaluate the prediction performance of five significant factors, effect-size estimates were separately calculated in both training set and testing set (Table S4), and were compared using the $\mathrm{Z}$ tests. At a significance level of 0.05 , the risk estimates of GDM for allergic diseases were reinforced in the testing set, differing slightly from that in the training set $(\mathrm{P}=0.036)$, which might be explained by the low prevalence of GDM in this study. Hence, GDM was not identified as a significant risk factor for allergic diseases.

Considering the possible existence of site-specific heterogeneity, the prediction of four significant factors (bedtime, outdoor activities, antibiotic use during childhood, and family history of allergic diseases) for allergic diseases was examined in Beijing and Tangshan, respectively, as shown in Table S5. As illustrated by the Z tests, only the magnitude of bedtime in predicting allergic diseases differed significantly between Beijing and Tangshan $(\mathrm{P}=3.70 \mathrm{E}-04)$, albeit statistical significance was observed in both sites. Given the significant differences in age and sex distributions, as well as the magnitude of risk prediction, the construction of nomogram models for childhood allergic diseases were done in Beijing and Tangshan, respectively. 


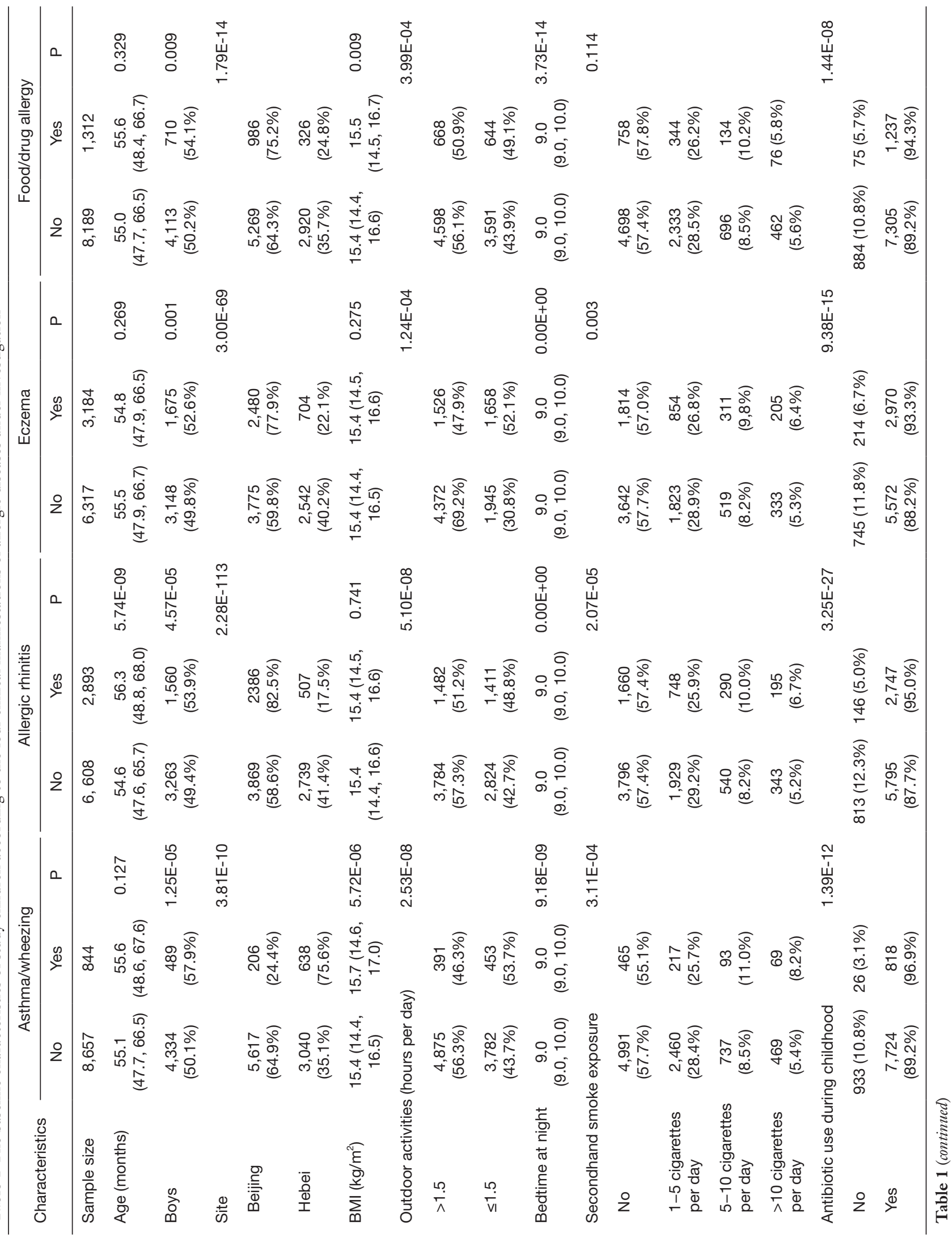




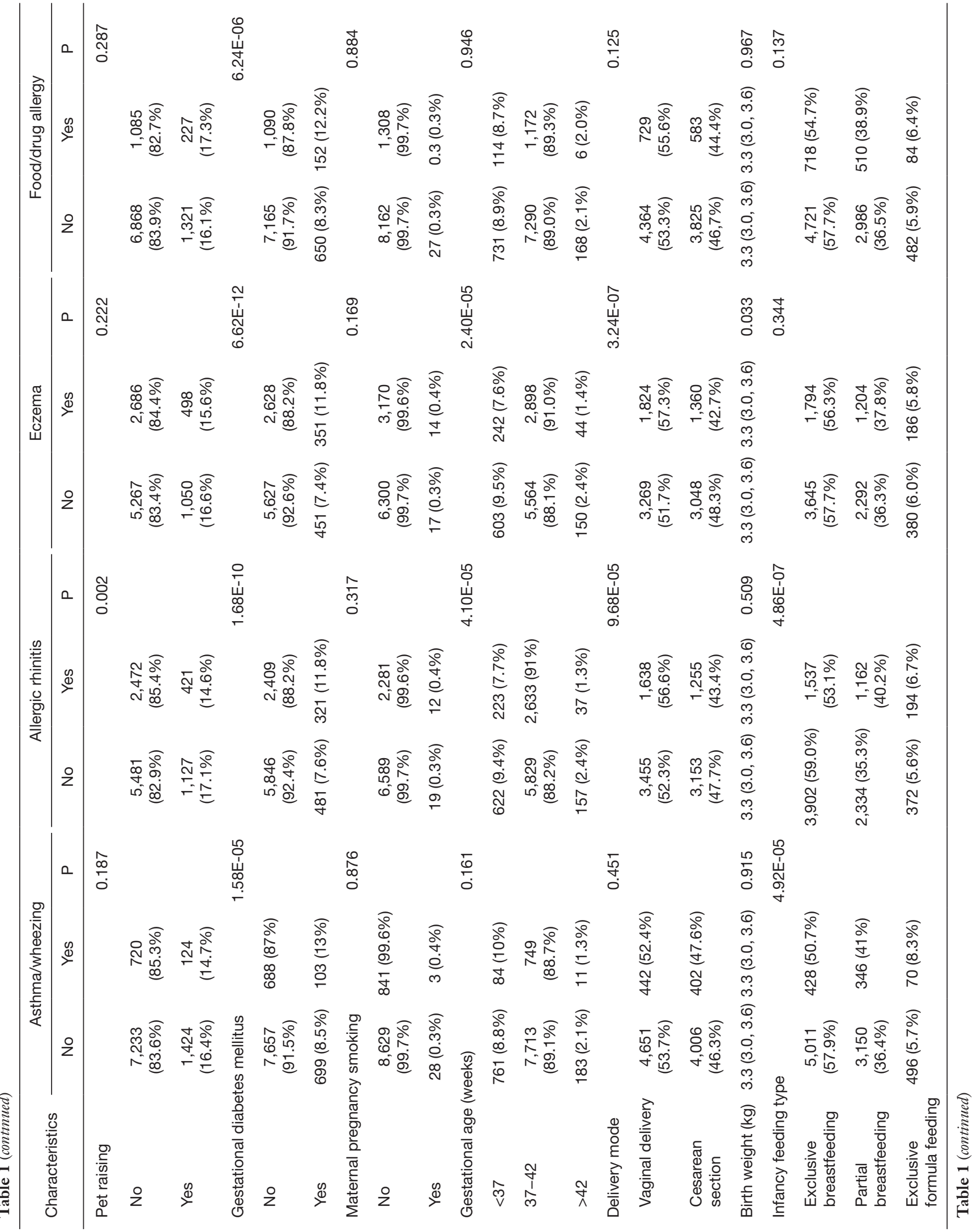




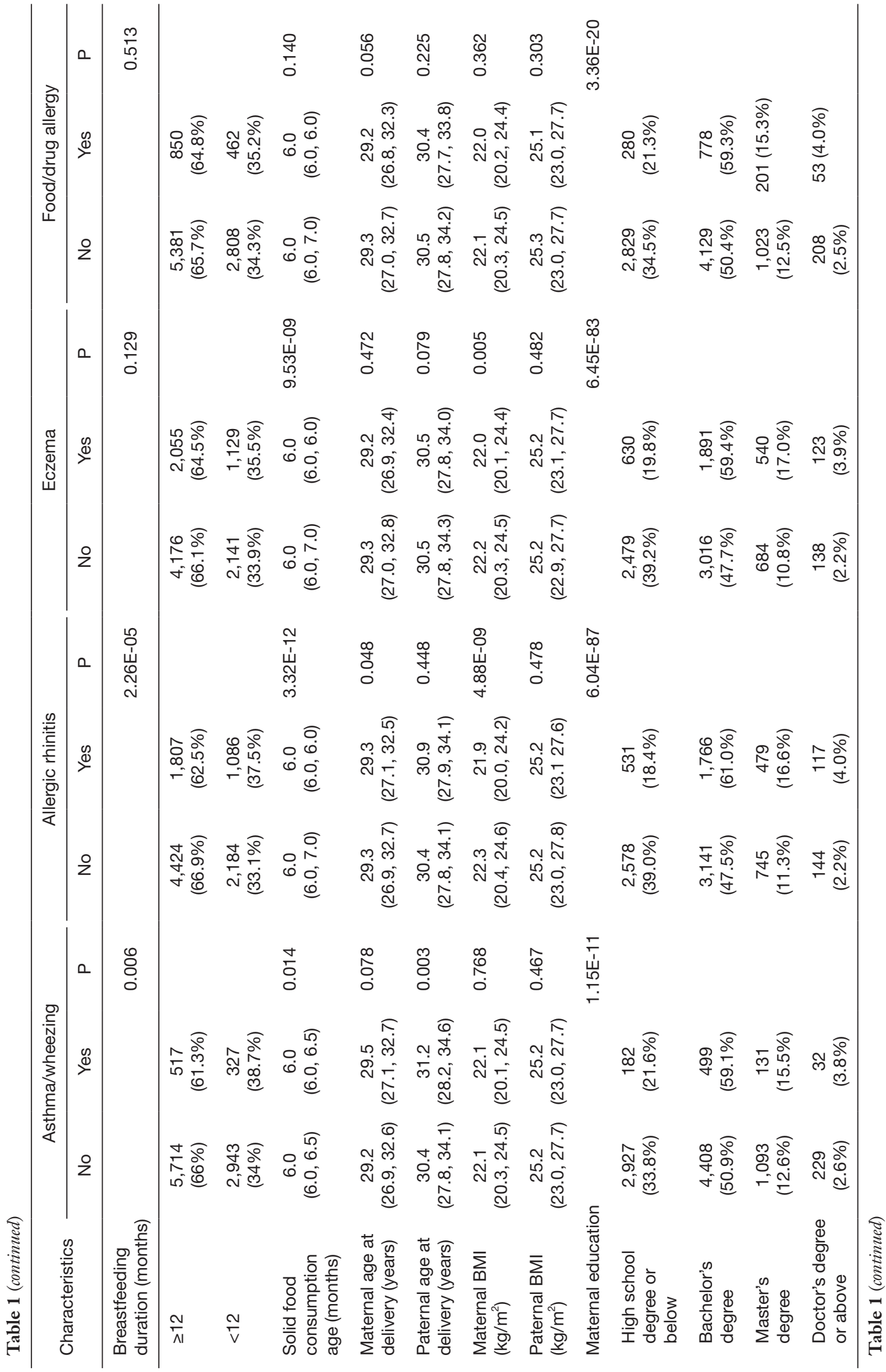




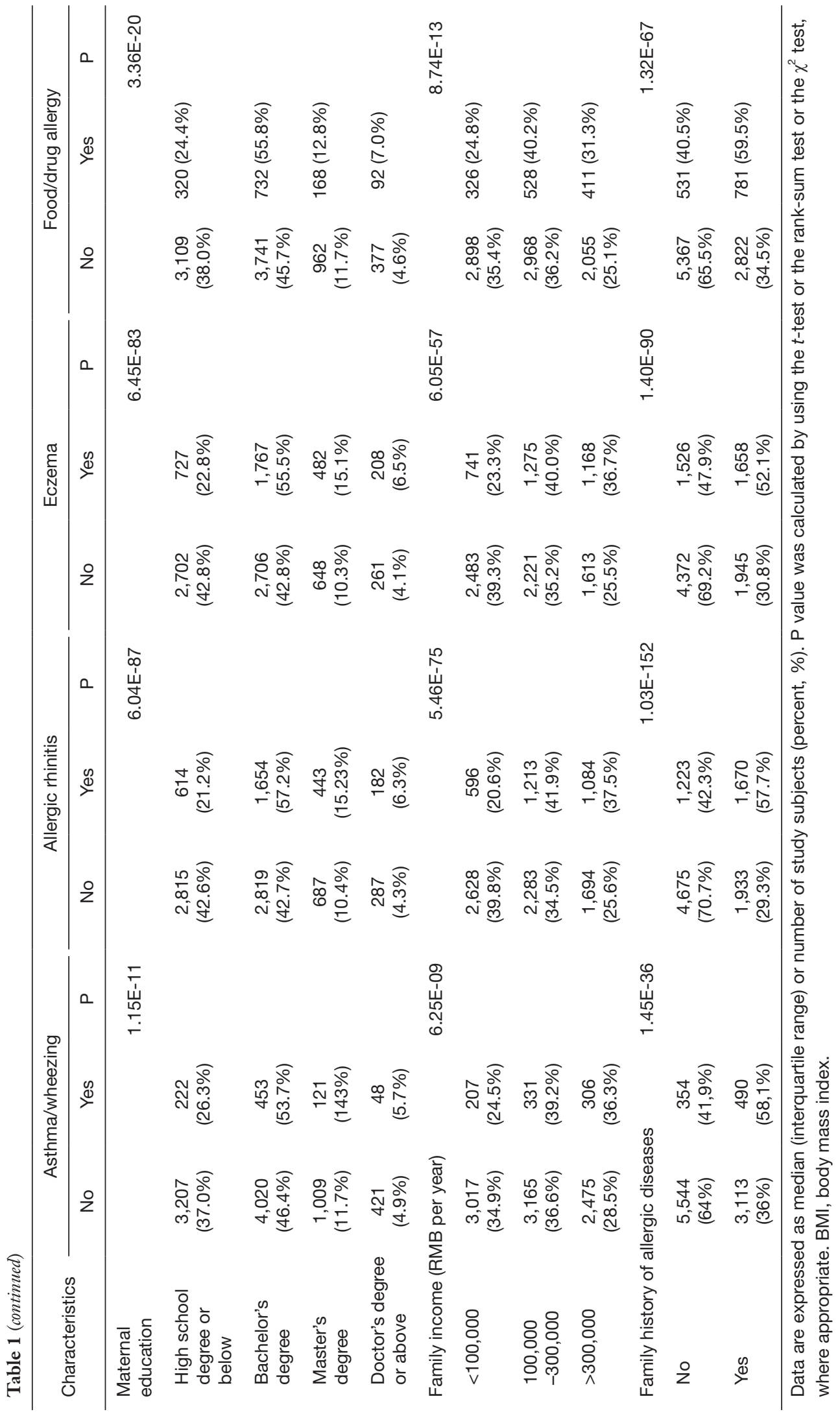




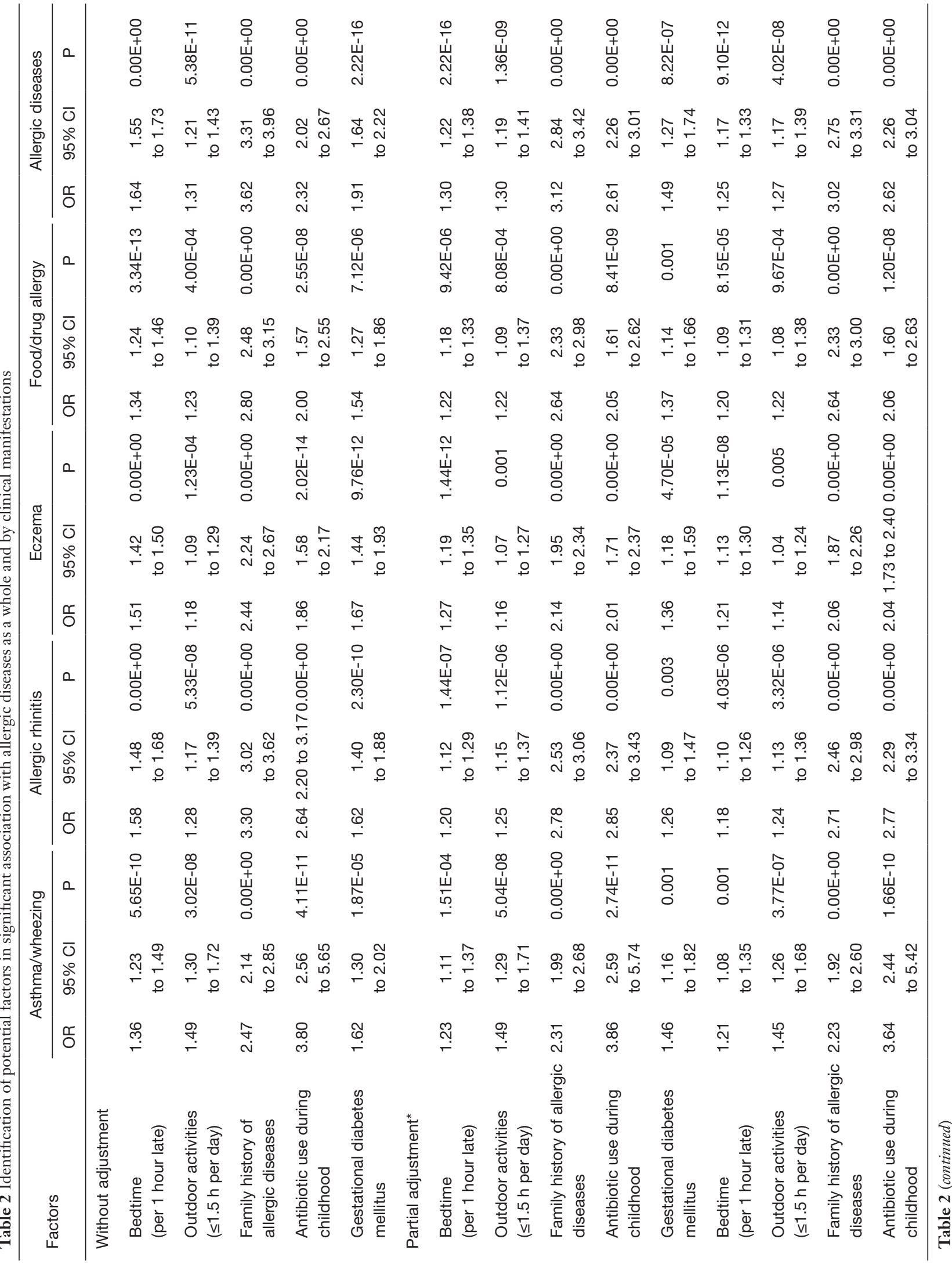




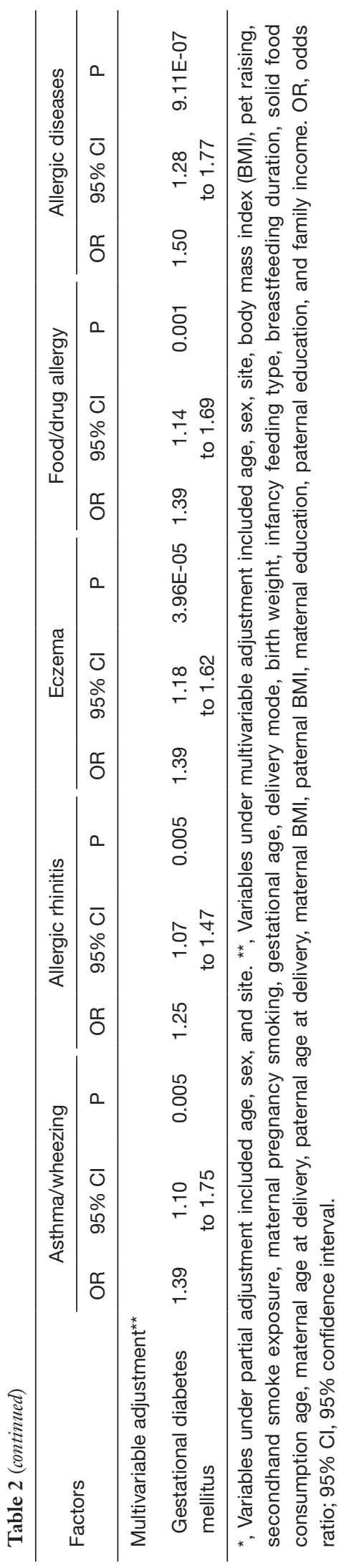

\section{Prediction performance assessment before modelling}

Prediction performance of the four significant factors associated with allergic diseases was reflected by comparing the two models, viz. the full model (all variables of interest in the survey) and the basic model (all variables except the four significant factors) in term of both calibration and discrimination statistics (Table 3). Significant improvement was seen after adding the four significant factors in predicting the presence of allergic diseases in both Beijing and Tangshan.

Additionally, decision curve analysis indicated that the net benefits gained by adding the four significant factors to the basic model were obvious among all children (Figure 1A), as well as among children from Beijing (Figure $1 B$ ) and Tangshan (Figure 1C).

\section{Risk prediction nomogram model}

Given the indispensable contribution of the four significant factors to the presence of allergic diseases, prediction nomogram models were constructed separately in Beijing (Figure $2 A$ ) and Tangshan (Figure $2 B$ ) to help calculate the risk of having allergic diseases in practice. In addition, the accuracy of prediction nomogram models was estimated to be $68 \%$ in Beijing and $69 \%$ in Tangshan (both $\mathrm{P}=0.00 \mathrm{E}+00$ ). Calibration curves are presented in Figure S1A (children from Beijing) and Figure S1B (children from Tangshan).

Taking the prediction model in Beijing an example, assuming a girl (0 points) with BMI of $24 \mathrm{~kg} / \mathrm{m}^{2}$ (15 points), maternal education of master's degree (40 points), family income more than $300,000 \mathrm{RMB}$ (5 points), bedtime at 9:00 pm (25 points), with antibiotic use during childhood (80 points), outdoor activities less than 1.5 hour per day (25 points), with maternal GDM (25 points), and family history of allergic diseases (100 points), adding up to 315 points, so the probability of having childhood allergic diseases is estimated to be $85 \%$.

\section{Combination of significant factors}

As an extension of the prediction of individual factors for allergic diseases, addition analyses focusing on the pairwise combinations of four significant factors were done for each clinical manifestation under investigation (Table 4). The risk for predicting clinical manifestations of allergic diseases was strongly reinforced for the combination between family history of allergic diseases and antibiotic use during 


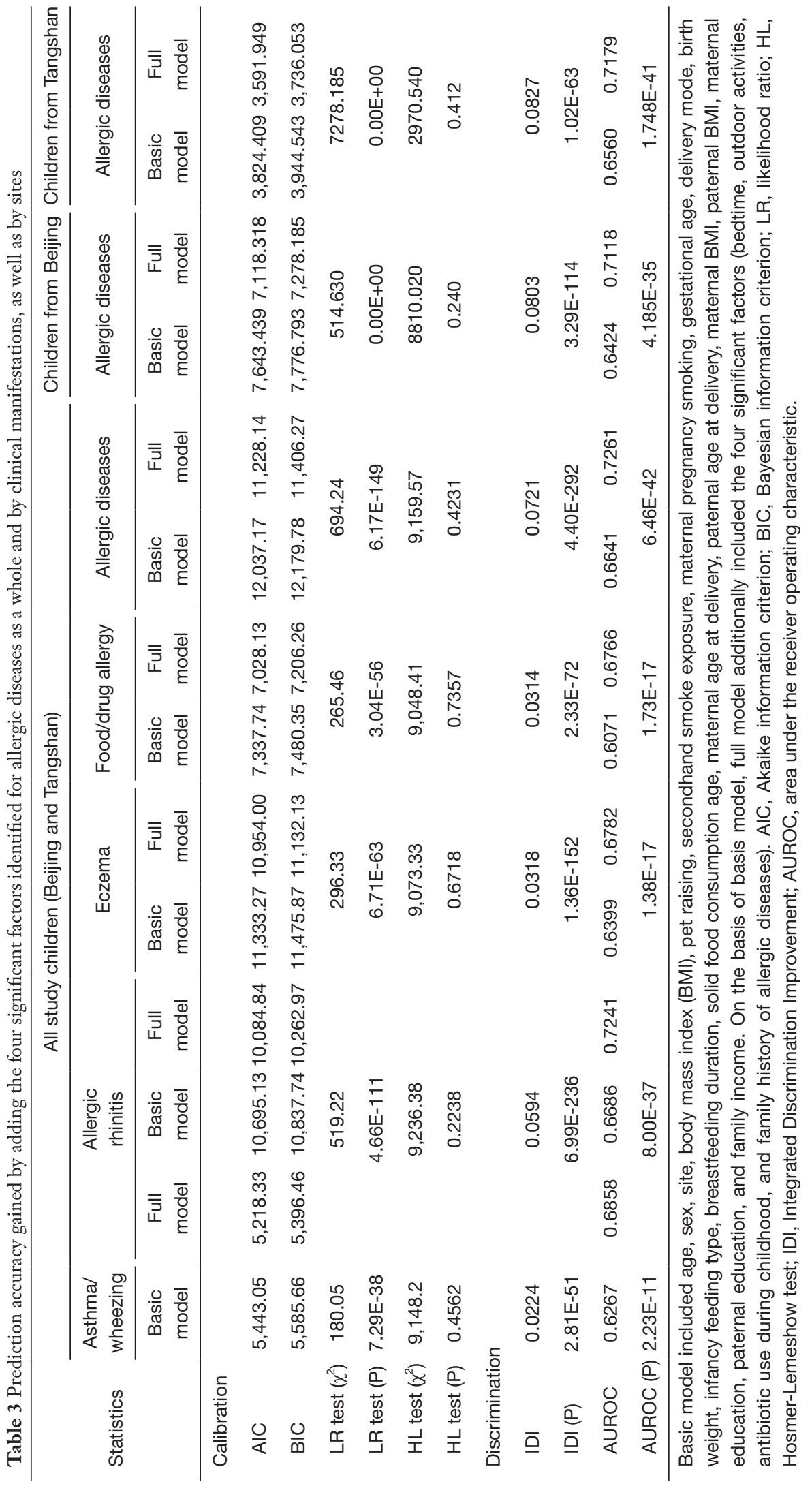



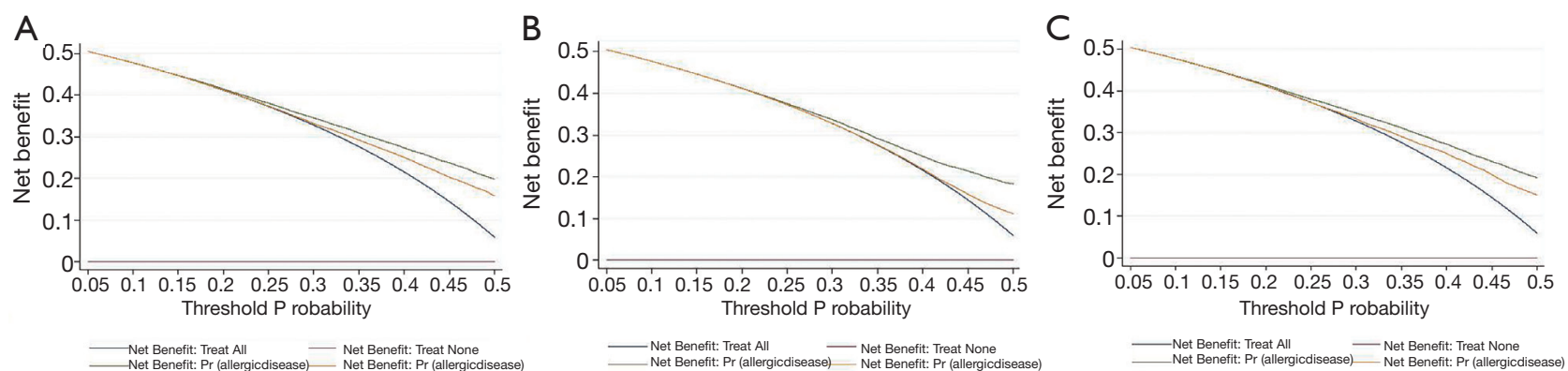

Figure 1 Decision curve analyses for childhood allergic diseases among all children (A), children from Beijing (B), and children from Tangshan (C).

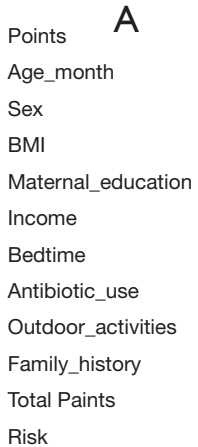

Risk

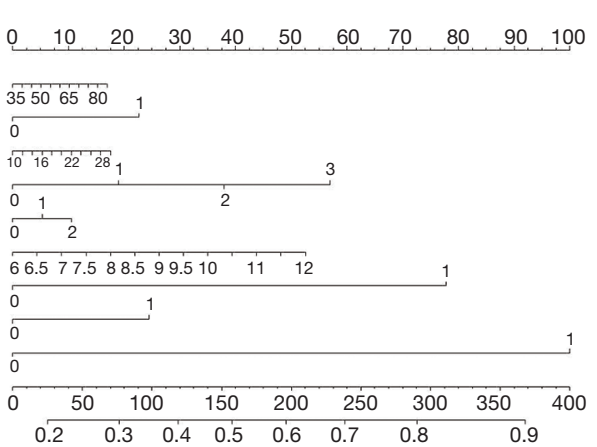

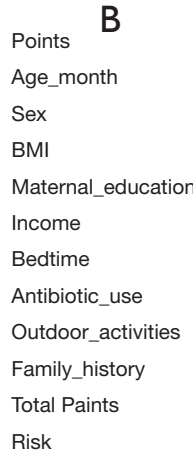

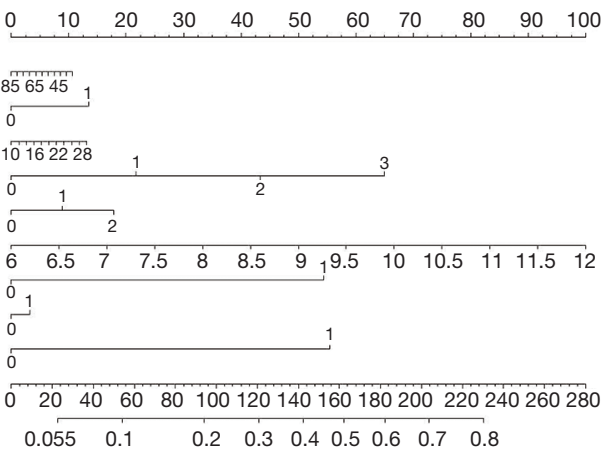

Figure 2 Prediction nomograms for allergic diseases of children from Beijing (A) and Tangshan (B). BMI, body mass index.

childhood compared to the reference group after adjusting for a wide panel of confounders under the multivariable Logistic regression analyses. For instance, taking the children without a family history of allergic diseases and without antibiotic use during childhood as a reference group, the risk of having asthma/wheezing was estimated to be 1.77 (95\% CI: 0.80 to 3.93 ) for children with a family history of allergic diseases and without antibiotic use during childhood, 3.02 (95\% CI: 1.79 to 5.12) for children without a family history of allergic diseases and with antibiotic use during childhood, and 6.56 (95\% CI: 3.88 to 11.06) for children with a family history of allergic diseases and with antibiotic use during childhood.

\section{Discussion}

In this large cross-sectional survey of 9,501 Chinese preschool-aged children, we aimed to identify potential factors associated with childhood allergic diseases, both in isolation and in combination. The key findings of this study are the identification of four potential factors, viz. bedtime, outdoor activities, antibiotic use during childhood, and family history of allergic diseases in predicting the significant risk of allergic diseases overall and by clinical manifestations, and particularly the four significant factors made an indispensable contribution in improving risk prediction capability. Importantly, the simultaneous presence of family history of allergic diseases and antibiotic use during childhood strikingly enhanced the risk of four clinical manifestations of allergic diseases. To the best of our knowledge, this is the first report that has examined the joint contribution of multiple potential factors to allergic diseases among Chinese preschool-aged children.

The burden of allergic diseases on the health and healthcare of children is increasing around globally over the last two decades (6). Allergic diseases include a constellation of related clinical manifestations, such as asthma/wheezing and allergic rhinitis, and they severely affect the quality of life in childhood and later adulthood. Currently, the precise causes of childhood allergic diseases are not fully understood, and endeavors in identifying and characterizing the risk profiles responsible for the development of allergic 
Table 4 The combination of the four significant factors identified in predicting allergic diseases

\begin{tabular}{|c|c|c|c|c|c|c|c|c|c|c|c|c|}
\hline Combination items ${ }^{*}$ & \multicolumn{3}{|c|}{ Asthma/wheezing } & \multicolumn{3}{|c|}{ Allergic rhinitis } & \multicolumn{3}{|c|}{ Eczema } & \multicolumn{3}{|c|}{ Food/drug allergy } \\
\hline \multicolumn{13}{|l|}{ Bedtime and outdoor activities } \\
\hline $\begin{array}{l}\text { Bedtime at 9:00 pm or earlier/ } \\
\text { outdoor activities (>1.5 h per day) }\end{array}$ & & Ref. & & & Ref. & & & Ref. & & & Ref. & \\
\hline $\begin{array}{l}\text { Bedtime at 9:00 pm or earlier/ } \\
\text { outdoor activities ( } \leq 1.5 \mathrm{~h} \text { per day) }\end{array}$ & 1.54 & $\begin{array}{c}1.27 \text { to } \\
1.87\end{array}$ & $1.42 \mathrm{E}-05$ & 1.27 & $\begin{array}{c}1.13 \text { to } \\
1.44\end{array}$ & $1.23 \mathrm{E}-04$ & 1.12 & $\begin{array}{c}0.99 \text { to } \\
1.26\end{array}$ & 0.065 & 1.01 & $\begin{array}{c}0.85 \text { to } \\
1.18\end{array}$ & 0.946 \\
\hline $\begin{array}{l}\text { Bedtime later than 9:00 pm/ } \\
\text { outdoor activities (>1.5 h per day) }\end{array}$ & 1.21 & $\begin{array}{c}0.97 \text { to } \\
1.51\end{array}$ & 0.090 & 1.29 & $\begin{array}{c}1.13 \text { to } \\
1.47\end{array}$ & 1.77E-04 & 1.17 & $\begin{array}{c}1.03 \text { to } \\
1.33\end{array}$ & 0.017 & 1.04 & $\begin{array}{c}0.87 \text { to } \\
1.24\end{array}$ & 0.649 \\
\hline $\begin{array}{l}\text { Bedtime later than 9:00 pm/ } \\
\text { outdoor activities ( } \leq 1.5 \mathrm{~h} \text { per day) }\end{array}$ & 1.61 & $\begin{array}{c}1.31 \text { to } \\
1.99\end{array}$ & 7.46E-06 & 1.52 & $\begin{array}{c}1.33 \text { to } \\
1.73\end{array}$ & $6.41 \mathrm{E}-10$ & 1.33 & $\begin{array}{c}1.03 \text { to } \\
1.33\end{array}$ & $1.30 \mathrm{E}-05$ & 1.56 & $\begin{array}{c}1.33 \text { to } \\
1.85\end{array}$ & $1.10 \mathrm{E}-07$ \\
\hline $\begin{array}{l}\text { Bedtime at 9:00 pm or earlier/ } \\
\text { family history of allergic diseases } \\
\text { (yes) }\end{array}$ & 2.39 & $\begin{array}{l}1.96 \text { to } \\
2.92\end{array}$ & $0.00 \mathrm{E}+00$ & 2.62 & $\begin{array}{c}2.30 \text { to } \\
2.98\end{array}$ & $0.00 \mathrm{E}+00$ & 2.10 & $\begin{array}{c}1.86 \text { to } \\
2.38\end{array}$ & $0.00 \mathrm{E}+00$ & 2.90 & $\begin{array}{c}2.45 \text { to } \\
3.43\end{array}$ & $0.00 \mathrm{E}+00$ \\
\hline $\begin{array}{l}\text { Bedtime later than 9:00 pm/family } \\
\text { history of allergic diseases (no) }\end{array}$ & 1.21 & $\begin{array}{c}0.96 \text { to } \\
1.53\end{array}$ & 0.103 & 1.18 & $\begin{array}{c}1.02 \text { to } \\
1.35\end{array}$ & 0.020 & 1.19 & $\begin{array}{l}1.05 \text { to } \\
1.35\end{array}$ & 0.008 & 1.41 & $\begin{array}{c}1.16 \text { to } \\
1.71\end{array}$ & 4.83E-04 \\
\hline $\begin{array}{l}\text { Bedtime later than 9:00 pm/family } \\
\text { history of allergic diseases (yes) }\end{array}$ & 2.46 & $\begin{array}{l}1.98 \text { to } \\
3.05\end{array}$ & $2.22 \mathrm{E}-16$ & 3.27 & $\begin{array}{c}2.5 \text { to } \\
3.75\end{array}$ & $0.00 \mathrm{E}+00$ & 2.35 & $\begin{array}{c}2.05 \text { to } \\
2.68\end{array}$ & $0.00 E+00$ & 3.27 & $\begin{array}{l}2.73 \text { to } \\
3.92\end{array}$ & $0.00 \mathrm{E}+00$ \\
\hline \multicolumn{13}{|c|}{ Antibiotic use during childhood and bedtime } \\
\hline $\begin{array}{l}\text { Antibiotic use during childhood } \\
\text { (yes)/bedtime later than 9:00 pm }\end{array}$ & 3.59 & $\begin{array}{l}2.18 \text { to } \\
5.91\end{array}$ & $5.44 \mathrm{E}-07$ & 3.05 & $\begin{array}{c}2.38 \text { to } \\
3.90\end{array}$ & $0.00 \mathrm{E}+00$ & 2.30 & $\begin{array}{l}1.85 \text { to } \\
2.86\end{array}$ & $8.66 \mathrm{E}-14$ & 3.07 & $\begin{array}{c}2.14 \text { to } \\
4.40\end{array}$ & $1.28 \mathrm{E}-09$ \\
\hline \multicolumn{13}{|c|}{ Outdoor activities and family history of allergic diseases } \\
\hline $\begin{array}{l}\text { Outdoor activities (>1.5 h per } \\
\text { day)/family history of allergic } \\
\text { diseases (no) }\end{array}$ & & Ref. & & & Ref. & & & Ref. & & & Ref. & \\
\hline $\begin{array}{l}\text { Outdoor activities (>1.5 h per } \\
\text { day)/family history of allergic } \\
\text { diseases (yes) }\end{array}$ & 2.27 & $\begin{array}{l}1.83 \text { to } \\
2.82\end{array}$ & $1.17 \mathrm{E}-13$ & 2.61 & $\begin{array}{c}2.29 \text { to } \\
2.98\end{array}$ & $0.00 \mathrm{E}+00$ & 2.20 & $\begin{array}{c}1.94 \text { to } \\
2.49\end{array}$ & $0.00 \mathrm{E}+00$ & 3.04 & $\begin{array}{l}2.56 \text { to } \\
3.62\end{array}$ & $0.00 \mathrm{E}+00$ \\
\hline $\begin{array}{l}\text { Outdoor activities ( } \leq 1.5 \mathrm{~h} \text { per } \\
\text { day)/family history of allergic } \\
\text { diseases (no) }\end{array}$ & 1.46 & $\begin{array}{l}1.17 \text { to } \\
1.82\end{array}$ & 0.001 & 1.18 & $\begin{array}{c}1.03 \text { to } \\
1.35\end{array}$ & 0.014 & 1.19 & $\begin{array}{c}1.06 \text { to } \\
1.35\end{array}$ & 0.004 & 1.41 & $\begin{array}{c}1.18 \text { to } \\
1.69\end{array}$ & 1.99E-04 \\
\hline $\begin{array}{l}\text { Outdoor activities ( } \leq 1.5 \mathrm{~h} \text { per } \\
\text { day)/family history of allergic } \\
\text { diseases (yes) }\end{array}$ & 3.16 & $\begin{array}{l}2.56 \text { to } \\
3.90\end{array}$ & $0.00 \mathrm{E}+00$ & 3.30 & $\begin{array}{c}2.88 \text { to } \\
3.77\end{array}$ & $0.00 \mathrm{E}+00$ & 2.25 & $\begin{array}{l}1.98 \text { to } \\
2.56\end{array}$ & $0.00 \mathrm{E}+00$ & 3.19 & $\begin{array}{c}2.67 \text { to } \\
3.81\end{array}$ & $0.00 \mathrm{E}+00$ \\
\hline
\end{tabular}

Table 4 (continued) 
Table 4 (continued)

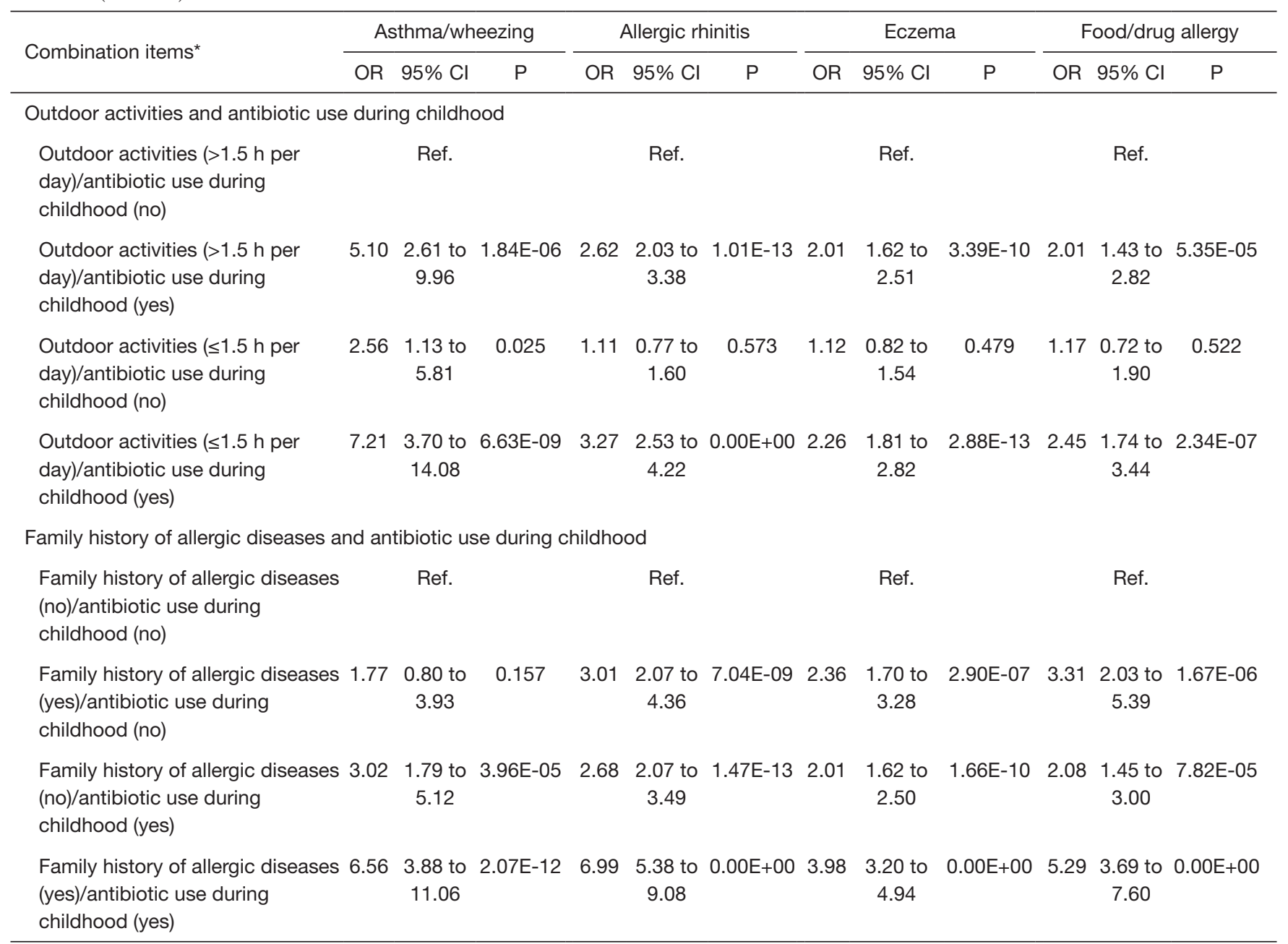

*Variables under multivariable adjustment included age, sex, region, body mass index (BMI), second-hand smoke exposure, pet raising, maternal pregnancy smoking, gestational age, delivery mode, birth weight, infancy feeding type, breastfeeding duration, solid food consumption age, maternal age at delivery, paternal age at delivery, maternal BMI, paternal BMI, maternal education, paternal education, and family income.

diseases are still ongoing.

In line with the observations of most previous studies $(17,18)$, we found an independent, significant, and consistent association of later bedtime with the risk of having allergic diseases among preschool-aged children from Beijing and Tangshan. The possible mechanisms underlying this association may be that sleep and the circadian rhythm have complex relationships with immune function and cytokine production related to the development of allergic diseases (19).

Besides, we also found that antibiotic use during childhood played a leading role in susceptibility to allergic diseases, consistent with the observations of most previous studies $(20,21)$. This finding is biologically plausible. It is widely recognized that the gut microbiota-immune system interaction impacts on the development of allergic diseases (22), and antibiotic administration during childhood in return can result in considerable changes in gut macrobiotics $(23,24)$. Meanwhile, we found an inverse association between outdoor activities and allergic diseases, which might be related to the reduction in vitamin $\mathrm{D}$ synthesis, which is implicated in the development of allergic diseases $(25,26)$. Not surprisingly, there is evidence that allergic diseases are, at least in part, inheritable (27-30), and so a positive family history of allergic diseases served as 
a determined risk factor in the development of childhood allergic diseases, as observed in the present study, as well as in other studies $(30,31)$.

Extending the findings of previous studies, we attempted to explore whether the combination of individual factors can enhance the risk prediction for the clinical manifestations of allergic diseases in this study. It is worth noting that family history of allergic diseases acted in an additive manner with antibiotic use during childhood when predicting the risk of each allergic manifestation. The molecular mechanisms behind this observation remain elusive and are subject to an ongoing debate. Nevertheless, this finding underscores a consolidated join impact of gut microbiota and genetics in predisposing children to allergic diseases. We agree that further validation of our findings in other independent groups is warranted.

\section{Limitations}

Despite the obvious strengths of this study, including a relatively large, population-based survey on preschool-aged children from Beijing and Tangshan in China, consideration of multivariable cofounding factors, construction of risk prediction nomogram models and explorations on possible combinations of significant factors, several possible limitations need to be acknowledged. Firstly, this study is cross-sectional in nature, precluding further comments on the cause-effect relationship. Secondly, our data were obtained through questionnaires filled in by the parents or guardians of involved children, and hence a recall bias cannot be excluded. Thirdly, all study children of Chinese descent are currently living in Beijing and Tangshan, and extrapolation of our findings to other racial or ethnical groups should be done with caution.

\section{Conclusions}

Taken together, via an analysis of survey data from 9,501 preschool-aged children, we identified four potential factors in significant association with allergic diseases overall and by clinical manifestations, and their contribution to improving risk prediction was indispensable. Importantly, family history of allergic diseases acted synergistically with antibiotic use during childhood. For practical reasons, we hope the present study will not remain just another endpoint of research instead of a start to establish background data to further explore potential risk factors, both in isolation and in combination, of childhood allergic diseases, and the possible molecular mechanisms.

\section{Acknowledgments}

We are grateful to all participating children, and their parents or guardians for their cooperation and willingness, as well as kindergarten teachers, and health physicians for their great help.

Funding: None.

\section{Footnote}

Reporting Checklist: The authors have completed the STROBE reporting checklist. Available at https://dx.doi. org/10.21037/tp-21-124

Data Sharing Statement: Available at https://dx.doi. org/10.21037/tp-21-124

Conflicts of Interest: All authors have completed the ICMJE uniform disclosure form (available at https://dx.doi. org/10.21037/tp-21-124). The authors have no conflicts of interest to declare.

Ethical Statement: The authors are accountable for all aspects of the work in ensuring that questions related to the accuracy or integrity of any part of the work are appropriately investigated and resolved. The study was conducted in accordance with the Declaration of Helsinki (as revised in 2013). The study was approved by the Ethics Committee of China-Japan Friendship Hospital (NO.: 2019-15-K10) and informed consent was taken from all the participants.

Open Access Statement: This is an Open Access article distributed in accordance with the Creative Commons Attribution-NonCommercial-NoDerivs 4.0 International License (CC BY-NC-ND 4.0), which permits the noncommercial replication and distribution of the article with the strict proviso that no changes or edits are made and the original work is properly cited (including links to both the formal publication through the relevant DOI and the license). See: https://creativecommons.org/licenses/by-nc-nd/4.0/.

\section{References}

1. Asher MI, Montefort S, Björkstén B, et al. Worldwide time trends in the prevalence of symptoms of asthma, allergic 
rhinoconjunctivitis, and eczema in childhood: ISAAC

Phases One and Three repeat multicountry cross-sectional surveys. Lancet 2006;368:733-43.

2. Wong GW, Leung TF, Ko FW. Changing prevalence of allergic diseases in the Asia-pacific region. Allergy Asthma Immunol Res 2013;5:251-7.

3. Li F, Zhou Y, Li S, et al. Prevalence and risk factors of childhood allergic diseases in eight metropolitan cities in China: a multicenter study. BMC Public Health 2011;11:437.

4. Chen Y, Zhu J, Lyu J, et al. Association of Maternal Prepregnancy Weight and Gestational Weight Gain With Children's Allergic Diseases. JAMA Netw Open 2020;3:e2015643.

5. Margolis JS, Abuabara K, Bilker W, et al. Persistence of mild to moderate atopic dermatitis. JAMA Dermatol 2014;150:593-600.

6. World Allergy Orgnization.White-Book-on-Allergy. Available online: https://www.worldallergy.org/wao-whitebook-on-allergy

7. Chen YL, Sng WJ, Wang Y, et al. Antibiotic overuse and allergy-related diseases: an epidemiological cross-sectional study in the grasslands of Northern China. Ther Clin Risk Manag 2019;15:783-9.

8. Woehlk C, von Bülow A, Kriegbaum M, et al. Allergic asthma is associated with increased risk of infections requiring antibiotics. Ann Allergy Asthma Immunol 2018;120:169-76.e1.

9. Foliaki S, Nielsen SK, Björkstén B, et al. Antibiotic sales and the prevalence of symptoms of asthma, rhinitis, and eczema: The International Study of Asthma and Allergies in Childhood (ISAAC). Int J Epidemiol 2004;33:558-63.

10. Anveden Berglind I, Alderling M, Meding B. Life-style factors and hand eczema. Br J Dermatol 2011;165:568-75.

11. Al-Sahab B, Atoui M, Musharrafieh U, et al. Epidemiology of eczema among Lebanese adolescents. Int J Public Health 2008;53:260-7.

12. Asher MI, Keil U, Anderson HR, et al. International Study of Asthma and Allergies in Childhood (ISAAC): rationale and methods. Eur Respir J 1995;8:483-91.

13. Solé D, Rosário Filho NA, Sarinho ES, et al. Prevalence of asthma and allergic diseases in adolescents: nine-year follow-up study (2003-2012). J Pediatr (Rio J) 2015;91:30-5.

14. Kim HY, Kwon EB, Baek JH, et al. Prevalence and comorbidity of allergic diseases in preschool children. Korean J Pediatr 2013;56:338-42.

15. Nwaru BI, Lumia M, Kaila M, et al. Validation of the Finnish ISAAC questionnaire on asthma against anti- asthmatic medication reimbursement database in 5-yearold children. Clin Respir J 2011;5:211-8.

16. Vickers AJ, Elkin EB. Decision curve analysis: a novel method for evaluating prediction models. Med Decis Making 2006;26:565-74.

17. Fishbein AB, Mueller K, Kruse L, et al. Sleep disturbance in children with moderate/severe atopic dermatitis: A casecontrol study. J Am Acad Dermatol 2018;78:336-41.

18. Deng X, He M, He D, et al. Sleep duration and obesity in children and adolescents: evidence from an updated and dose-response meta-analysis. Sleep Med 2021;78:169-81.

19. Lange T, Dimitrov S, Born J. Effects of sleep and circadian rhythm on the human immune system. Ann N Y Acad Sci 2010;1193:48-59.

20. Zou Z, Liu W, Huang C, et al. First-Year Antibiotics Exposure in Relation to Childhood Asthma, Allergies, and Airway Illnesses. Int J Environ Res Public Health 2020;17:5700.

21. Singh S, Sharma BB, Salvi S, et al. Allergic rhinitis, rhinoconjunctivitis, and eczema: prevalence and associated factors in children. Clin Respir J 2018;12:547-56.

22. Sarkar A, Yoo JY, Valeria Ozorio Dutra S, et al. The Association between Early-Life Gut Microbiota and LongTerm Health and Diseases. J Clin Med 2021;10:459.

23. Rachid R, Stephen-Victor E, Chatila TA. The microbial origins of food allergy. J Allergy Clin Immunol 2021;147:808-13.

24. Francino MP. Antibiotics and the Human Gut Microbiome: Dysbioses and Accumulation of Resistances. Front Microbiol 2016;6:1543.

25. Hawrylowicz CM, Santos AF. Vitamin D: can the sun stop the atopic epidemic? Curr Opin Allergy Clin Immunol 2020;20:181-7.

26. Hollams EM, Teo SM, Kusel M, et al. Vitamin D over the first decade and susceptibility to childhood allergy and asthma. J Allergy Clin Immunol 2017;139:472-481.e9.

27. Ferreira MA, Vonk JM, Baurecht H, et al. Shared genetic origin of asthma, hay fever and eczema elucidates allergic disease biology. Nat Genet 2017;49:1752-7.

28. Marques CR, Costa GN, da Silva TM, et al. Suggestive association between variants in IL1RAPL and asthma symptoms in Latin American children. Eur J Hum Genet 2017;25:439-45.

29. Fiuza BSD, Silva MJ, Alcântara-Neves NM, et al. Polymorphisms in DENND1B gene are associated with asthma and atopy phenotypes in Brazilian children. Mol Immunol 2017;90:33-41.

30. Bjerg A, Hedman L, Perzanowski MS, et al. Family history 
of asthma and atopy: in-depth analyses of the impact on asthma and wheeze in 7- to 8-year-old children. Pediatrics 2007;120:741-8.

31. Ochoa-Avilés C, Morillo D, Rodriguez A, et al. Prevalence

Cite this article as: Yang $M$, Deng $X$, Wang S, Wang K, Niu W, Zhang Z. Risk factors for allergic diseases: a cross-sectional survey of 9,501 Chinese preschool-aged children. Transl Pediatr 2021;10(8):1989-2005. doi: 10.21037/tp-21-124 and risk factors for asthma, rhinitis, eczema, and atopy among preschool children in an Andean city. PLoS One 2020;15:e0234633. 